\title{
Josef Stern, Metaphor in Context (Cambridge, MA: MIT Press, 2000)
}

\author{
Elisabeth CAMP \\ Harvard Society of Fellows
}

Metaphor is a crucially context-dependent linguistic phenomenon. This fact was not clearly recognized until some time in the 1970's. Until then, most theorists assumed that a sentence must have a fixed set of metaphorical meanings, if it had any at all. Often, they also assumed that metaphoricity was the product of grammatical deviance, in the form of a category mistake. To compensate for this deviance, they thought, at least one of the sentence's constituent terms underwent a meaning-changing 'metaphorical twist', which deleted the objectionable selection restriction or semantic marker (e.g., Levin 1977) or turned one of the term's fixed set of connotations into its denotation (e.g., Beardsley 1962).

This situation changed as theorists began to pay more serious attention to how metaphors actually function. First, it was pointed out that not all sentences used metaphorically are logically or even pragmatically absurd (Cohen 1975). Second, it became increasingly obvious that in the context of different sentences, and in the context of the same sentence as uttered by different speakers on different occasions, the same word could be used metaphorically to express many, very different meanings. Semantic theories became increasingly bloated as theorists attempted to encompass all this variety within the lexicon. Eventually, semantic theories of metaphor were largely abandoned. Instead, theorists generally maintained either that metaphors are a type of speaker meaning, on which a speaker says one thing in order to mean something else (e.g., Grice 1975, Searle 1979), or else that metaphors don't have any distinctive 'meaning' at all, but simply cause certain distinctive effects in their hearers (e.g., Davidson 1984, Rorty 1987).

Philosophers of language have devoted much energy in the last 30 years to investigating the various ways in which context can affect communicated and P.O. Box 1354, 9600 Garsington Road, Oxford, OX4 2DQ, UK. 
content. Some of them have recently begun to bring the resulting insights and tools to bear on metaphor, and in particular to revisit the idea that metaphor should be treated semantically. Some of these theorists, such as David Hills (1997), invoke comparatively controversial assumptions about semantic meaning generally. Josef Stern, by contrast, argues in Metaphor in Context (2000) that metaphor is semantic on a fairly standard, broadly Kaplanian understanding of that term. He argues that metaphor exhibits systematic constraints on interpretation, constraints which most people would agree require a semantic analysis. Therefore, if the arguments Stern offers are successful, even quite mainstream semanticists should feel considerable pressure to admit that metaphor is a semantic phenomenon - a conclusion which would in turn significantly reconfigure the theoretical terrain. Further, because his arguments turn on particular details of metaphorical interpretation, evaluating those arguments forces us to get clearer about the specifics of metaphor than philosophers have previously done. Finally, his arguments parallel others that have been or could be given to support semantic analyses of other contextually variable phenomena. Thus, a close examination of his arguments about metaphor may have implications for those discussions as well.

These are by no means the only virtues of Metaphor in Context. Stern has a sensitive ear for the nuances of metaphorical interpretation, which he applies to a wide range of real-life examples, drawn from both literary and practical contexts. He offers sophisticated analyses of the rich cognitive and non-cognitive effects that metaphor can engender; he thereby makes clear why and how metaphor serves important communicative and cognitive functions. And he has important insights to offer about the relation between metaphor and a range of other phenomena, such as irony and religious discourse. These all make Metaphor in Context a significant and valuable book. However, I will focus exclusively on Stern's main claim: that metaphor is a semantic phenomenon. After spelling out Stern's analysis in $\S 1$, I take up his argument that metaphor should be treated semantically in $\$ 2$, and his arguments that it should be treated in the specific manner he suggests in $\S 3$.

\section{1. 'Mthat' and 'Dthat'}

Stern argues that expressions used metaphorically should be analyzed on analogy with Kaplan's (1978) treatment of demonstratives in terms of the 'Dthat' operator. To this end, Stern postulates an unpronounced "metaphoricity" operator 'Mthat' at the level of logical form, which, when prefixed to a term or phrase $\phi$, transforms $\phi$ into a context-sensitive expression in accordance with the following rule (Stern 2000, 115): 
For every context $c$ and for every expression $\phi$, an occurrence of 'Mthat [ $\phi]$ ' in a sentence $S(=\ldots$ Mthat $[\phi] \ldots)$ in $c$ (directly) expresses a set of properties $P$ presupposed to be m-associated with $\phi$ in $c$ such that the proposition $<\ldots P \ldots>$ is either true or false in the circumstance of $c$.

So, for instance, Stern thinks that a metaphorical utterance of

(1) Juliet is the sun

has as its implicit logical form

(1) Juliet Mthat['is the sun'].

'Mthat' contributes the set of properties which happen to be m-associated with 'is the sun' in the actual context of utterance-say, being worthy of worship, nurturing of one's soul, fairer than all others, and so on (Stern 2000, 206) - to the proposition expressed, thereby producing the proposition <Juliet, is worthy of worship, nurturing of one's soul, fairer than all others, and so on $>$ as the semantic content of (1) in that context. (In fact, Stern is committed to the view (cf. 134) that (1) is at least five-ways ambiguous, because the 'Mthat' operator can be appended to any term or phrase in the sentence, producing at least the following options in addition to the fully literal reading: "Mthat['Juliet is the sun']"; "Mthat['Juliet'] is the sun"; "Juliet is 'Mthat['the sun']"; and "Juliet Mthat['is the sun']." The last of these captures Romeo's intended reading: Romeo is claiming that Juliet is a certain way, one which is metaphorically describable as being the sun. Thus, while Stern's semantic theory avoids positing much lexical ambiguity, it does introduce considerable structural ambiguity.)

While 'Mthat' is obviously modeled on 'Dthat', there are also important differences between them. One difference is that where the output of 'Dthat' depends upon the content of the embedded expression $\phi$, the output of 'Mthat' depends upon the set of presuppositions that are m-associated with that expression in that context of utterance. These presuppositions need not be true, or even believed true, but they should determine a univocal (if complex) metaphorical meaning for a given term in a given context. Because the same term may be m-associated with different presuppositions in different contexts, Stern's rule explains why metaphorical interpretation is contextually variable. And because distinct co-referring terms typically have at least slightly different presuppositions m-associated with them, it also explains why the substitution of co-referring terms typically alters the overall utterance's metaphorical content.

A second difference is that although both 'Dthat' and 'Mthat' are supposed to be directly referential, 'Dthat' is partially denotational, in the sense that it contributes the object denoted by its embedded definite description to the 
proposition expressed. By contrast, Stern says, 'Mthat' is like 'I' or 'here' in being parametric. Parametric terms have semantic characters which determine parameters, whose values are in turn supplied by context. Such terms are therefore "thoroughly non-denotational" in the following sense: the very fact that the term occurs in that context of utterance "ipso facto" assigns a value to its parameter; "we do not survey the context, on the model of denotation, to see which of its elements satisfies the condition stated in the rule of its character" (Stern 2000, 92). As a result, although linguistic competence purportedly requires speakers to know the general "schematic rule for 'Mthat $[\Phi]$ ' that underlies our ability to interpret all expressions metaphorically" (Stern 2000, 201), it does not require speakers themselves to have an independent "conceptualized representation" (Stern 2000,93) of the properties that are m-associated with a particular expression $\phi$ in that context. This fact helps, Stern thinks, to explain why metaphor can add such rich expressive - and even cognitiveresources to a language (Stern 2000, 187ff.): it enables speakers to refer to and think about properties for which they have no other representation.

The semantic rule for 'I' constrains the parameter's value very tightly. By contrast, the rule for 'here' is rather more flexible about which factors fix the value in any given case: the relevant extent of space may be quite large or small, and may be made salient in a variety of ways (by pointing to a map, by observing a passing scene, and so on). In this respect, 'Mthat' is more like 'here' than like 'I'. Although it is supposed to be quite determinate which properties are m-associated with an expression $\phi$ in a given context, Stern maintains that a wide variety of factors can cause a property to be m-associated with an expression. A property $F$ may be m-associated with a given term $\phi$, he says, because $F$ is a stereotypical or a normal property of $\phi$-type things, because some salient $\phi$-type thing exemplifies $F$, because $\phi$ has historically been metaphorically associated with $F$-ness, or for some other reason altogether. The task of a semantic theory of metaphor, on Stern's view, is simply to determine the contents of metaphorical utterances, given information about which properties are m-associated with the relevant expressions in that context. "What makes metaphor a single linguistic phenomenon," he says, is just "that one formal semantic relation governs the context-dependence of its interpretation" (Stern 2000, 113). He denies that any unified theory can be given about the "grounds" of metaphor-about what determines that those particular properties are in fact m-associated with those expressions in that context - and thinks that past theories of metaphor have failed in large part because they have sought necessary and sufficient conditions for m-association in general (Stern 2000, 112). Indeed, the theory of m-association seems to fall outside the theory of meaning altogether (much like a theory of, say, salience). Different linguistic communities could apparently rely upon radically different mechanisms of m-association; if so, this would be a merely empirical fact on Stern's view, one that poses no threat either to the unity of metaphor or to philosophical theorizing about metaphor. 
A third difference between 'Dthat' and 'Mthat' concerns the sorts of entities they deliver as semantic values. Kaplan originally defined 'Dthat' only for singular terms (including, of course, definite descriptions). As a result, 'Dthat $[\phi]$ ' always contributes an individual (or a set of individuals) to the proposition expressed. But very many metaphors are predicative: think of familiar examples like (1) or

(2) Sally is a block of ice.

Stern therefore defines 'Mthat $[\phi]$ ' in general so that it contributes properties to propositional contents; in this respect it is more like a predicative demonstrative (e.g. 'that sound') than like 'Dthat' (Stern 2000, 107). Obviously, though, not all metaphors are predicative. We need a further story about how 'Mthat' applies to noun-phrase metaphors, as in

(3) The cunning fox is up to his familiar tricks, or

(4) Einstein over here just stuck his finger into the electrical socket,

and also to 'whole-sentence' metaphors, such as

(5) Hark! The sun's first light breaks o'er the mountaintop,

uttered, say, by Romeo as Juliet appears at her bedroom window. Stern does make some moves toward an extension of 'Mthat' to nominative metaphors like (3) (Stern 2000, 225-9). On the most plausible version, the metaphorical nominative phrase is analyzed roughly as follows. We first transform the nominative phrase's descriptive content into a predicate, which we plug into 'Mthat' to isolate the set of properties $P$ which are m-associated with that predicative expression in this context. We then form a new nominative phrase from $P$ plus the original quantifier. ${ }^{1}$ (3) thus becomes:

(3) [The $x$ : Mthat['cunning fox'] $x$ ] is up to his old tricks again.

We can analyze a name used metaphorically, as in (4), by prefixing a 'Dthat' operator to the front of a definite description formed in the manner just described, as in:

(4) Dthat['[The $x$ : Mthat['Einstein']x]'] over here just stuck his finger into the electrical socket.

These modifications do seem to deliver the intuitively appropriate propositional contents - although it's still not at all clear how to apply the rule for 
'Mthat' to whole-sentence metaphors like (5). Given Stern's claim to be laying bare the logical form of sentences containing metaphorical expressions, we might perhaps complain that these modifications reveal his view to be more radical, and more ad hoc, than advertised. Metaphorical and literal readings of a single sentence like

(6) Einstein has come up with another groundbreaking theory

must now be assigned quite disparate logical forms, because the metaphorical reading must be analyzed as in (4). Of course, something must account for the different interpretations of (6), but the Stern-style (4) departs significantly from, and introduces significantly more complexity than, the logical form syntacticians would otherwise assign to the name in (6). By contrast, a pragmatic theory leaves the intuitive logical form intact. Such a complaint doesn't show that Stern's theory is incoherent or false, of course, but it does increase its theoretical cost, which in turn increases the need to establish that metaphor can't or shouldn't be analyzed in more parsimonious pragmatic terms. It is to this argument that I now turn.

\section{A Plea for Semantics}

The form of Stern's argument for a semantic analysis of metaphor is straightforward and compelling. There are, he claims, significant, systematic constraints on metaphorical interpretation. Because "it is difficult to see how we might account for these constraints in terms of use or mutual beliefs and expectations," he argues, "we must attribute to metaphor the semantic structure, or meaning, necessary for the requisite condition to apply" (Stern 2000, 70). The first set of interpretive constraints he presents, which I'll discuss here, are intended merely to establish the general claim that some form of semantic analysis is called for. The second set of constraints, which I'll take up in $\S 3$, aim to establish the specific analysis in 'Mthat'.

Exploiting a sentential version of the classic "conjunction reduction" test, Stern offers the following sentences as "semantically ill-formed" cases of verb phrase anaphora:

(7) The largest blob of gases in the solar system is the sun, and Juliet is, too.

(8) Juliet is the sun, and Achilles is, too.

He claims that the only available interpretations of the second conjuncts in these cases are those "copied" from a charitable interpretation of the first conjunct. This is supposed to be precisely analogous to the way in which, for

(9) John may leave tomorrow, and Harry too, 
the interpretation of 'may' in the second conjunct is automatically "copied" from its interpretation in the first, so that if we read the first conjunct as claiming that John has permission to leave, we cannot read the second as saying that it's possible that Harry will leave (Stern 2000, 69). Thus, Stern claims that 'is, too' in (7) inherits a literal reading from the first conjunct, and that the resulting sentence is malformed by virtue of containing a category mistake. (8) is less bad than (7), he thinks, because the second conjunct inherits a metaphorical character from the first. But (8) too is illformed, because "the statement must 'shift' contexts in the course of its interpretation" to produce distinct contents for that character in each conjunct (Stern 2000, 216).

I simply disagree with Stern's reading of the data here. First, notice that the intuition that (7) and (8) are semantically ill-formed (supposing we have intuitions about distinctively semantic ill-formedness) can be explained by pointing out that each sentence employs a single definite description to refer to two distinct objects in the same context. To show that the ill-formedness arises from constraints on interpreting the predicative material, Stern needs to demonstrate that the ill-formedness arises even without the interpretive constraint introduced by the definite description-for instance, if the definite description is replaced with an indefinite one. But if (7) and (8) are altered in this way, then I no longer share the intuition that they are illformed. First, I don't believe that the 'category mistake' produced by interpreting the second conjuncts literally would render them semantically ill-formed, as opposed to merely pragmatically absurd. ${ }^{2}$ Second, I think the second conjuncts of each sentence can be interpreted separately from the first. Stern admits this; his claim is just that that these "imposed interpretations" carry "a feeling of play or pun," and that this feeling "gives away the underlying semantic ill-formedness of the strings" (Stern 2000, 70). However, we don't yet have any argument that this "feeling of play or pun" reveals a distinctively semantic infelicity, as he claims. ${ }^{3}$

Indeed, it seems that the relevant infelicity in (7) and (8) cannot be the product of a semantic constraint. First, the infelicity is diminished or absent in cases where Stern's theory predicts it should remain. On his view, a sentence like

(10) Juliet and Achilles are each diamonds in their own different ways

should be even worse than (8), because the very same occurrence of 'diamond' must be assigned multiple metaphorical contents simultaneously. This should be just like attempting to assign different senses of 'may' for John and Harry in

(11) John and Harry may each leave tomorrow in their own different ways. 
But the desired reading of (11) is again utterly unavailable, while (10) is just fine. In a similar vein, contrast the relative differences between the pair of (8) and

(12) Juliet is a diamond in her own way, and Achilles is too,

on the one hand, and on the other, the pair of (9) and

(13) John may leave tomorrow in his own way, and Harry too.

The reading on which the two clauses are interpreted differently is much more easily available for (12) than for (8). Indeed, Stern himself admits that "it is possible to cancel the implication of univocality at the level of content," by adding a clause like "but not in the same way" to the end of the second conjunct of (8) (Stern 2000, 70, fn. 49). But cancelability is the classic test for establishing that a given reading is merely pragmatic. By contrast, it is just as impossible to read 'may' differently in each of the two conjuncts of (13) as it is for the original case of (9). The fact that the assumption of univocality is cancellable for (8) but not for (9) suggests that the interpretive constraint governing (8) may be a merely pragmatic one.

Second, the infelicity is present in prima facie analogous cases for which a semantic explanation is unavailable. ${ }^{4}$ Variants of (7) and (8) which split the conjuncts into separate sentences, as in

(14) The largest blob of gases in the solar system is a sun. And Juliet is a sun.

(15) Juliet is a sun. And Achilles is a sun.

are still bad, even though there is no syntactic constraint forcing a single reading for both tokens of 'sun'. Much the same infelicity can also be generated when two distinct expressions whose semantic values are commonly associated are used metaphorically in close proximity, as in

(16) Rosaline is the milky mysterious moon. And a bursting atomic bomb is the sun.

Here, though, all distinctively semantic sources for the infelicity have been eliminated. Intuitively, the infelicity arises because 'moon' and 'sun' are being interpreted according to such different background assumptions.

We also find the same in felicity in cases other than metaphor, for which Stern at least would grant that the appropriate explanation is pragmatic. It sounds nearly as bad to mix strict and loose uses of a term, as in

(17) It is silent in this specially constructed experimental chamber, and on this street, too, 
(Bezuidenhout 2001, 181), where the first conjunct is true on a strict reading of 'silent' and the second conjunct true only on a considerably looser understanding of the term. Similarly, it is very difficult to hear just one conjunct of

(18) John is a real genius, and Sam is too,

as ironic. But Stern dismisses a semantic analysis of irony out of hand: we are not, he says, "even tempted to posit an ironic meaning in the utterance in addition to the ordinary literal meanings of the words used" (Stern 2000, 233); "whatever controversy surrounds the status of metaphorical meaning, the ironic 'meaning' of an utterance is surely not a semantic meaning" (Stern 2000, 232).

Because the infelicity in examples (14) through (18) cannot have a primarily semantic source, and because these cases seem to be relevantly analogous to (7) and (8), Stern needs to provide an independent motivation for the claim that (7) and (8) demand a distinctive, semantic explanation. By contrast, despite his claim to the contrary, it looks as though a pragmatic view can account for all these cases of infelicity - in (7), (8), (10), and (14) through (18) - in terms of "mutual beliefs and expectations." When a hearer encounters the first conjunct of (7), for instance, the speaker's description of the sun in literal, scientific terms leads the hearer to expect that the rest of the utterance should be interpreted in the same way. This expectation is abruptly undermined when he is confronted with the second conjunct, which relies on a more mythological set of associations with the sun. Something similar happens in (8), though the incongruity is somewhat diminished, for two reasons. First, both conjuncts are interpreted metaphorically. Second, in both cases a person is described metaphorically as the sun, and so there is some overlap in which features of the sun are relevant. When there is even less overlap, as in

(19) Juliet is the sun, and a bursting atomic bomb is too.

then the infelicity is increased. The incongruity that is generated in (8) results from the fact that, although Juliet and Achilles are both people, they are very different people: she is a sweet, beautiful young girl; he is a fierce, angry male warrior. Many of the particular resemblances relevant for interpreting the first conjunct are thus irrelevant for the second. The interpretive surprise, and hence the infelicity, disappears when the need for such an interpretive reconfiguration is signaled explicitly, as in (10) or (12).

The explanation I've just sketched is almost identical to that offered by Stern himself, minus his insistence on assigning metaphor a semantic status. $\mathrm{He}$ too invokes conversational presuppositions, which he takes to be a 
function of conversational participants' "mutual beliefs and expectations." He writes:

In all these examples we interpret the first occurrence of the metaphor relative to one presupposition set, and continue, prima facie in the same context, to interpret another occurrence of the same metaphor ... relative to presuppositions that are inconsistent with the first set. The result violates the rule of Presuppositional Inconsistency, thereby generating a mixed metaphor. ... Here the rules that govern metaphorical interpretation are the same rules of rational cooperative linguistic behavior that govern the appropriateness of utterances in general. The one difference is that metaphor does not typically require a unique set of presuppositions ... (Stern 2000, 130-1; emphasis added.)

One is tempted to conclude from this that Stern's complex lexical machinery isn't yet doing any explanatory work in the case of metaphor. By contrast, the pragmatic explanation just sketched can account for the infelicity we find both with metaphor and with loose talk and sarcasm. Thus, for all we've seen so far, a pragmatic analysis of metaphor is both more parsimonious and more general than a semantic one.

\section{The Actual Context Constraint}

The second set of arguments Stern offers are designed more specifically to establish his particular analysis of metaphor. Stern argues that, just like demonstratives, metaphorical expressions always fix their contents by appealing to features of the actual context of utterance, and so contribute an invariant content to the proposition expressed, regardless of the circumstance at which that proposition is evaluated. He dubs this constraint on interpretation the "actual context constraint" (Stern 2000, 212), and claims that we see it at work when metaphorical expressions are embedded in sentences containing modal terms and belief- and speech- reporting clauses.

Let's consider the modal case first. On Stern's view, an utterance of

(20) Juliet might have been the sun

must be interpreted to mean that Juliet might have possessed those very features which she would be claimed actually to possess by a metaphorical utterance of the simpler sentence

(1) Juliet is the sun

in that same context of utterance (Stern 2000, 206). This does capture one possible interpretation. Imagine, for instance, that Romeo says "Juliet is the sun," and his rival, Paris, responds with (20), thereby denying that Juliet is 
in fact as Romeo characterizes her but allowing that she might have been that way: worthy of worship, nurturing of one's soul, fairer than all others, and so on. However, it is also possible for the content of the metaphorical phrase in (20) to be fixed relative to alternative circumstances. So, imagine that Paris responds to Romeo with (21) instead:

(21) As matters stand, Juliet's no sun. If she had married me, though, then she might have been the sun. She could have been the leading lady of Verona, and all the other ladies would have deferred to her.

The content contributed by 'the sun' here is very different than it was for Romeo's utterance. For one thing, where Romeo's utterance treated Juliet's virtues as like the sun's light in being natural and original, Paris's utterance attributes the possibility of a highly artificial importance to her, roughly of being the center of Veronese social life. The two metaphorical meanings of 'the sun' in (1) and (21) are thus plausibly not just distinct, but incompatible: Juliet could not be both ways at once. ${ }^{5}$ Alternatively, we can (rather anachronistically) imagine Romeo's comrade, Benvolio, responding to Romeo's utterance of (1) with something like

(22) If we were living after a nuclear apocalypse, then Juliet could have been the sun. After all, she's pale, cold, and distant, and that's how the sun would be then. But I can say she sure isn't the Tuscan sun.

Here again, Benvolio's utterance fixes a content for 'the sun' which is incompatible with Romeo's.

The simplest and most intuitive explanation for these variations in content is that Paris's and Benvolio's meanings are fixed with reference to the counterfactual circumstances mentioned in their utterance's antecedent clauses. Paris is imagining Juliet as she would be if she married him; this imagined-Juliet raises different resemblances with the sun to salience, and thereby determines a different metaphorical content, than actual-Juliet does. Benvolio, by contrast, is imagining the sun as it would be after a cataclysmic change, and this imagined-sun raises different resemblances with Juliet to salience. All this is easily accommodated within a pragmatic analysis, on which both sentences are literally false - Juliet wouldn't in fact be the sun in either of the imagined circumstances-but are interpreted metaphorically according to presuppositions which the speaker raises to relevance by mentioning the imagined circumstances in the antecedent, in 'interaction' with presuppositions about the subject under discussion.

If responses to Romeo's utterance such as (21) and (22) do occur in the same context of utterance as (1) itself, though, then Stern's actual context constraint is violated. To avoid this conclusion, Stern must argue that the utterances of (21) and (22) themselves alter the context, by shifting the 
presuppositions in play. To this end, he suggests, following Stalnaker (1999), that we treat antecedent conditionals as "explicit supposition[s] that [are] added (at least for the duration necessary to evaluate the consequent) to the initial context set of presuppositions," and that we analyze the subjunctive mood as "a conventional device for indicating that prior presuppositions to the contrary are being (temporarily) suspended" (Stern 2000, 207). So, while Stern admits that Paris's and Benvolio's utterances fix their contents relative to counterfactual situations, these situations are supposed to be contributed to the presupposition set of the actual context of utterance by the use of the conditional and subjunctive.

Stern is surely right that responses like (21) and (22) don't feel fully cooperative: they do seem to impose some sort of presuppositional shift. And there's a lot to be said in favor of Stalnaker's analysis of conditionals and the subjunctive. The crucial question, though, is whether these points serve to establish Stern's primary claim: that metaphor exhibits distinctive interpretive constraints which necessitate a semantic treatment. And here, I think the answer is 'no'. In effect, Stern's analysis entails that simply mentioning a counterfactual situation introduces it into the set of actual presuppositions. But if this is right, then we seem to have no means for distinguishing suppositions that specify the circumstances of evaluation from 'actual' contextual presuppositions. Without a way to tease these two sets of suppositions apart, though, there is no force to Stern's claim that, "like the character of an indexical, the character of the metaphor constrains its content by limiting its contextual source to actual presuppositions - even when we evaluate its truth in nonactual circumstances" (Stern 2000, 197). ${ }^{6}$

More importantly, we find a sharp disanalogy here between expressions used metaphorically and expressions that really are semantically constrained to fix their contents relative to the actual context. For genuine demonstratives - including those whose interpretation depends upon presuppositions - the two sets of suppositions can be teased apart rather easily. Contrast (21) and (22) with

(23) If George had started a dot-com, then he might have been that rich,

(24) If our society cared more about education and less about sports, then Alice would be that rich,

where 'that rich' functions demonstratively. In these cases, the interpretation of 'that rich' is genuinely independent of the antecedent. It requires determination by a comparison class which is independently and antecedently salient in the conversational context, and it can only be read to mean that George or Alice might have been wealthy according to the standard presupposed to be associated with that comparison class. The mention of dot-com founders or of education or sports in the antecedent cannot itself 
alter the relevant comparison class or standard. Thus, in this case the conditional only shifts the suppositions that specify the circumstances of evaluation; the demonstrative's content really is dependent on actual contextual presuppositions.

We find just the same contrast between metaphor and genuine demonstratives when we turn to Stern's second application of the actual context constraint, involving belief reports and indirect discourse. On Stern's view, the interpretation of sentences like

\section{(25) Romeo said/believes that Juliet is the sun}

should be constrained in precisely the same way as the interpretation of sentences like

(26) She said/believes that she's going to be that rich by next year.

The contents of both 'the sun' and 'that rich' should always be fixed relative to the actual contexts in which (25) or (26) are uttered, even when presuppositions have shifted so that the embedded sentence would fix a different content if it were now uttered on its own.

By default, all interpretation is guided by currently operative presuppositions, including especially presuppositions about the actual speaker's own attitudes. As a result, so long as no additional information is available about what Romeo himself thinks or has said about Juliet, (25) will naturally be read as the actual context constraint predicts: as meaning that Romeo said or believes the content that the speaker of (26) would express if he himself uttered the embedded sentence. For instance, suppose that Paris had previously uttered (21). If he were to go on to utter (25), then his utterance would naturally be taken to mean that Romeo said or believes that Juliet is the most important figure in Veronese social life.

However, (25) can also be read as reporting Romeo's utterance or belief with Romeo's intended interpretation. Imagine that Paris and Benvolio are engaged in a debate about Romeo's feelings for Juliet, and suppose that both of them overheard Romeo's original soliloquizing utterance of (1). Or imagine merely that it's mutual knowledge between them that Romeo has been mooning about after Juliet, and that he believes she's worthy of worship and an exemplar of natural beauty and goodness, and so on. In such a situation, the embedded sentence in (25) would most naturally be assigned the same content as that of Romeo's own original utterance. Indeed, suppose that only Benvolio overheard Romeo's soliloquy. If Paris were to paraphrase (25) with his preferred interpretation, as saying that Romeo said/believes that Juliet is the most important figure in Veronese social life, then Benvolio could appropriately disagree, insisting that that's not what Romeo meant at all, and certainly not what he actually said. 
Stern admits that the second reading of (25), with Romeo's intended interpretation, is available. He argues that this poses no threat to his theory, though, because in these cases the speaker temporarily adopts the reportee's point of view, thereby importing those presuppositions into the actual context of utterance, just as in the modal case. (Here, though, Stern grants that these "adopted presuppositions" are not "added to my own context set, even temporarily"; they are "insulated" from my own "native" presuppositions," but, he claims, no less actual for that). Further, the speaker is supposed to be committed to adopting these presuppositions for reasons entirely independent of the use of metaphor. The commitment is imposed, Stern says, simply in virtue of the speaker's "use of the linguistic construction for reporting": "I must adopt the reportee's point of view," he claims, "on pain of either acting irrationally (contrary to my own desire to report his belief) or exposing a kind of linguistic incompetence on my part (with respect to either or both metaphor and belief reports)" (Stern 2000, 213).

However, linguistic competence with expressions like 'said that' and 'believes that' does not impose any such constraint. For instance,

(27) Bill says that the lying SOB is honest

can be an acceptable report of Bill's utterance, even though Bill himself would be quite unwilling to utter the embedded sentence. As Kaplan (ms.) and others have pointed out, we do have a normal practice of reporting others' utterances and beliefs in ways that significantly depart from their own preferred modes of expression. More succinctly, we employ both de dicto and de re reports of others' speech and beliefs.

Stern claims (p.c.) that he is only interested in explaining de dicto reports containing metaphor, and so that the behavior of metaphor in de re reports needn't concern him. However, the very possibility of distinguishing between de re and de dicto interpretations of metaphorical utterances undermines the claim that metaphors obey the actual context constraint. In de dicto interpretation, the assumptions governing interpretation shift from the actual speaker's attitudes to those of the reportee; the claim that a given class of expressions obeys the actual context constraint entails the claim that those expressions must be interpreted de re in reporting contexts where the actual speaker's interpretive assumptions would determine a different semantic value from the reportee's. And indeed, in reporting contexts genuine demonstratives do always automatically jump out of the scope of the reported attitude, to have their content fixed by the actual context of utterance. Genuine demonstratives do always automatically jump out of the scope of the reported attitude, to have their content fixed by the actual context of utterance. In a case like (26), that is, it is simply not possible for the reporter to "adopt" the reportee's distinct interpretation of the demonstrative. If there did happen to be a general requirement that reporting 
statements be interpreted de dicto, then this might explain the fact that the actual context constraint was violated in those contexts: the de dicto reporting constraint might trump the actual context constraint. In the absence of such a general reporting constraint, however, we have no explanation for the fact that the actual context constraint is violated for metaphor, but not for demonstratives. Thus, the very possibility of using metaphor to report speech and attitudes in ways that echo the reportee's presuppositions, where these come apart from the reporter's own presuppositions, demonstrates that metaphorical interpretation can depend on alternative contexts.

\section{A Possible Alternative?}

In order for Stern's argument to succeed, he needs to establish two claims: first, that metaphor exhibits certain interpretive constraints; and second, that those constraints cannot be explained in merely pragmatic terms. This is, I think, exactly the right way to argue for a semantic analysis of any contextually variable phenomenon. However, metaphor does not in fact exhibit the interpretive constraints that Stern claims for it. He has identified certain patterns of default interpretation and of infelicity, but these patterns are merely defeasible, as they should not be if they were genuinely semantic. Moreover, these patterns of interpretation can be explained on a pragmatic analysis in terms of "mutual beliefs and expectations."

An alternative semantic view of metaphor may be available. Metaphor does not obey the actual context constraint, but there are other semantically context-sensitive terms which don't obey it either. So-called "broad indexicals," 7 including for example graded adjectives like 'tall', 'old', 'good', and 'rich', are "parametric" in the sense Stern intends, and often depend crucially upon conversational presuppositions, as metaphor does. The crucial difference between them and "narrow indexicals" like 'I' and 'this' is that broad but not narrow indexicals are susceptible to binding-which is just to say that narrow indexicals obey the actual context constraint while broad indexicals don't. It is at least prima facie plausible that all of the counterexamples I've offered could be accommodated by an analysis that treats the metaphorical expression in question as potentially bindable.

Supposing that a coherent account of metaphors along these lines could be developed, though, this view would still face precisely the challenge that Stern rightly set for himself. It is not enough just to show that the account is predictively adequate: it needs to be at least as plausible and parsimonious as the available alternatives. Having modified the view so that it no longer makes the false prediction that expressions used metaphorically obey the actual context constraint, we now require a substitute for that constraint in order to motivate the specific account on offer. I'm not sure what this would be. Given that a pragmatic explanation of metaphor explains the phenomena by invoking only general, independently motivated principles of 
interpretation, and given that it introduces no additional syntactic or semantic complexity, I suggest that we should prefer it unless and until such a constraint is identified.

This conclusion should not distract us from the value of Metaphor in Context. Although Stern himself puts the semantic arguments at the center of his book, it would still be interesting, important, and controversial even without them. His discussion of paraphrase, cognitive content and pictures in chapter 7 is itself worth the price of admission, and there are many other topics to be mined throughout the book. I recommend it to every serious student of metaphor, and indeed to anyone who enjoys exploring the rich nuances of linguistic interpretation. ${ }^{8}$

\begin{abstract}
Notes
${ }^{1}$ Stern doesn't address nominative metaphors other than definite descriptions, but we need an analysis that's sufficiently general to work for metaphors like 'No mere sparrow can be elected president' or 'Fewer scrappy mutts are running for president this year and more tailwagging lapdogs of privilege.' The general method I describe seems like the most natural extension of what I take to be the most plausible option Stern does offer.

${ }^{2}$ See my (2004).

${ }^{3}$ We clearly can get the same sorts of 'imposed', punning, infelicitous readings for sentences involving conjunction reduction which play on semantic ambiguity, as in

(i) The logs were holding up the bank, and the masked man was too.

Here the fact that 'bank' is semantically ambiguous is clearly relevant, but even then it is still not clear that we should describe the infelicity as a distinctively semantic one. The infelicity also depends upon knowledge about which interpretation of each clause a speaker is likely to intend; we might therefore treat the infelicity as a pragmatic one that depends, in part, upon semantic facts. Thanks to Adam Sennet for pressing the general point about 'imposed' readings of reduced sentences.

${ }^{4}$ Cf. Zwicky and Saddock (1975).

${ }^{5}$ Stern suggests (p.c.) that Paris and Romeo in this scenario share a common, general interpretation - something like "being unparalleled among one's peers"- but disagree over its evaluation. I hear the two interpretations as considerably more specific, and incompatible. Other cases are possible in which a response shares no plausible, common interpretation with Romeo's original utterance: for example,
\end{abstract}

(i) If Juliet had been an ancient Amazonian, then she might have been the sun. Then she could have blazed with fury on the battlefield, like Achilles.

If there is any claim that Juliet is unparalleled here, it surely results just from the uniqueness entailed by the definite description rather than from the metaphorical meaning itself.

${ }^{6}$ Actually, I think I can generate a reading on which (22) is interpreted according to one set of circumstances and evaluated according to another, neither of which belong to the actual context. Imagine that a rumor is circulating that Juliet might be sent to school in Florence, and that Romeo and Benvolio are speculating about how this would change her personality. Romeo 
insists that Juliet would still be the sun - still worthy of worship, glowing with natural, unspoiled beauty and virtue - even after spending time in the big city. Benvolio replies (again anachronistically):

(i) Juliet might be the sun after living in Florence, but only the sun as it would be if we were living after a nuclear apocalypse. If she goes, city life will make her even more pale, cold, and distant than she is now, and that's how the sun would be in such a circumstance. But I can say that if she goes, she sure won't be the sun as we know it.

I admit that this isn't a normal utterance, but I do think it is possible. Again, though, Stern can accommodate this reading simply by insisting that all the mentioned counterfactuals are added to the set of actual presuppositions.

${ }^{7}$ Cf. e.g. Stanley $2000,411$.

${ }^{8}$ Thanks for valuable discussions with Kent Bach, Andy Egan, John Hawthorne, Richard Heck, John MacFarlane, Bernard Nickel, Marga Reimer, and Dmitri Tymoczko. Thanks especially to Josef Stern for his helpful comments on this study and on a critical discussion at the Pacific APA.

\section{References}

Beardsley, Monroe. (1962) "The Metaphorical Twist," Philosophy and Phenomenological Research 22:3, 293-307.

Bezuidenhout, Anne. (2001) "Metaphor and What is Said: A Defense of a Direct Expression View of Metaphor," Midwest Studies in Philosophy 25, 156-186.

Camp, Elisabeth. (2004) "The Generality Constraint and Categorial Restrictions," The Philosophical Quarterly 54: 215, 209-231.

Cohen, Ted. (1975) "Figurative Speech and Figurative Acts," Journal of Philosophy 71, $669-684$.

Davidson, Donald. (1984) "What Metaphors Mean," in Inquiries into Truth and Interpretation, Oxford: Clarendon Press.

Grice, Paul. (1975) "Logic and Conversation," in Speech Acts: Syntax and Semantics vol. 3, P. Cole and J. L. Morgan (eds.), New York: Academic Press.

Hills, David. (1997) “Aptness and Truth in Verbal Metaphor," Philosophical Topics 25:1, $117-153$.

Kaplan, David. (ms.) "De re beliefs."

Kaplan, David. (1978) "Dthat," in Pragmatics: Syntax and Semantics vol. 9, P. Cole (ed.), New York: Academic Press.

Levin, Samuel. (1977) The Semantics of Metaphor, Baltimore: Johns Hopkins University Press.

Rorty, Richard. (1987) "Unfamiliar Noises I: Hesse and Davidson on Metaphor," Proceedings of the Aristotelian Society supp. vol. 61, 283-296.

Searle, John. (1979) "Metaphor," in Expression and Meaning: Studies in the Theory of Speech Acts, Cambridge: Cambridge University Press.

Stalnaker Robert. (1999) "Indicative Conditionals," in Context and Content, Oxford: Oxford University Press.

Stanley, Jason. (2000) "Context and Logical Form," Linguistics and Philosophy 23, 391-434.

Stern, Josef. (2000) Metaphor in Context, Cambridge, MA: MIT Press.

Zwicky, Arnold and Jerrold Saddock. (1975) "Ambiguity Tests and How to Fail Them," in Syntax and Semantics vol. 4, J. Kimball (ed.), New York: Academic Press. 